
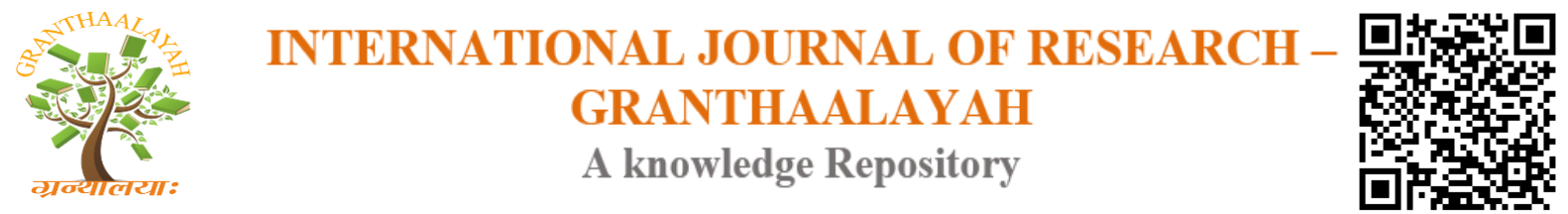

Management

\title{
A STUDY ON NEW HIRING STRATEGIES TO MANAGE TALENT CRISIS AT ENTRY LEVEL FROM THE PERSPECTIVE OF RECRUITERS AND FRESH GRADUATE ENGINEER JOB SEEKERS
}

\author{
Sufia Rehman *1, Dr. S. Shahid Mazhar ${ }^{2}$ \\ ${ }^{* 1}$ Research Scholar, Faculty of Management \& Research, Integral University, Lucknow, INDIA \\ ${ }^{2}$ Jr. Associate Professor, Faculty of Management \& Research, Integral University, Lucknow, \\ INDIA
}

DOI: https://doi.org/10.29121/granthaalayah.v4.i9.2016.2530

\section{ABSTRACT}

Internet apart from influencing life of people has also emerged as a key HR tool for acquiring talent. Traditional HR strategies are being modernized, driven by technology and innovations. The remarkable popularity of internet \& Social Media Sites, lower hiring cost \& res ponce time and competitive advantage has allured the recruiters not only to use it for effective branding but also for hiring. They offer a great source of talent pool, as almost every fresh graduate / professional has Social Media account. Professional networking with social media as a recruitment tool is influencing with offer of better platform to both recruiters and this study discusses the Impact \& effectiveness of New Hiring Strategies. Their advantages and limitations over traditional methods and their role in making or breaking the job opportunity. The study used data from secondary sources also personal interviews with industry professionals and Job seekers were conducted. A comprehensive analysis of the new trends has been done and described through various graphs and diagrams.

The findings of the survey show a significant change in trend from traditional recruitment methods to modern techniques. However there remains good scope for improvement in utilizing the various benefits of the new strategies

Keywords:

Human Resource Management, Internet, Recruitment Strategies, Social Media Networks.

Cite This Article: Sufia Rehman, and Dr. S. Shahid Mazhar, "A STUDY ON NEW HIRING STRATEGIES TO MANAGE TALENT CRISIS AT ENTRY LEVEL FROM THE PERSPECTIVE OF RECRUITERS AND FRESH GRADUATE ENGINEER JOB SEEKERS” International Journal of Research - Granthaalayah, Vol. 4, No. 9 (2016): 14-29.

\section{INTRODUCTION}

"It is not the strongest of the species, nor the most intelligent that survives. It is the one that is the most adaptable to change." -Charles Darwin. 
Today the Human Resource Management in organizations is working at a backbreaking speed trying to cope with the challenges of talent management at entry level jobs for Fresh Graduate Engineers. The recruitment strategies are becoming more exciting and revolutionized with the integration of innovative tools and technology. Continuous growth in technology and Internet based communication channels has transformed the recruitment landscape and is fast substituting the traditional method of recruitment. What started as a supplement to traditional paper based lengthy process has today conquered over the whole recruitment process. From job posting, accepting resumes and job applications, screening (on the basis of the websites / web habits), selection process rolling out final offers to back ground check the full recruitment cycle has completely digital.

Internet as a recruiting tool first emerged in the mid-1990s bringing a radical change to corporate recruiting with the popular media naming it as "recruiting revolution" because of the benefits for the recruiters. It has already influenced and changed the nature of the traditional recruitment process. Online recruitment and the use of new emerging technologies give many advantages like improved speed by which candidates can be matched with live vacancies that the modern recruiter are attracted to adopt these techniques. It was projected that the recruitment industry's "future is on the net" .I Internet technology has empowered corporate websites, suppliers and job seekers to become more sophisticated and interactive In fact today the employers are required to actively market themselves by establishing a well-executable recruitment program to find quality candidates and better hiring decisions, effective both in terms of time and cost.

Social networking websites or Social media as the name strikes we all have images of Facebook, Twitter, Linked-in flashing in our minds. Social media has made a dynamic impact on people's lives. One in every four individual already has a Facebook account. Leaving digital footprints is in vogue with today's generation. Social media offers ample of opportunities to be gained through it other than networking. The concept of recruiting candidates through social platforms as talent pool or for Job postings is popularly known as social media Recruiting or social recruiting. It uses social media profiles, blogs, and online communities as a talent database to search for passive candidate information. It also uses social media for job posting either through HR vendors or through crowd sourcing. Here both the employers, job seekers and others share job openings within their online social networks. It not only helps to open avenues for a job seeker previously unheard of, but also for the employer as it has made the availability of a massive pool of active and passive job seekers. Today not only the recruiters can access and contact potential employees but also the jobseekers can search for desired jobs with a simple click of a button. This practice is quite liked by the Human Resource team in quite a few organizations. Reputed organizations are fast redesigning their overall business strategy, and the use of social networking sites for searching the right talent is quite prevalent. These organizations not only launch a wide net through social websites but also best use them to narrow down their search for specific requirements with great ease and have manage to develop hiring strategies to near precision. The new age recruitment strategies are not only use full in searching right and viable candidates for high level positions but they are also very helpful in finding candidates for entry level positions. Organizations are using social media sites for reference check of the prospective candidates. Social networking websites like Face book, Twitter, and Linked In are promising as effective job search tools for the job seekers as well. 


\section{OBJECTIVE OF THE STUDY}

- To study the emergence of new recruiting strategies for effective hiring of Fresh Graduate Engineers at entry level.

- To study the effectiveness of new hiring techniques as recruitment strategy from Recruiters perspective.

- To study recruitment through Social Media Sites from the perspective of a New Graduate job seeker.

\section{LITRATURE REVIEW}

New Recruitment strategies using social media and mobile Technology is comparatively a nascent research area since social networking sites like Facebook, Linked-In and Twitter came into existence after 2003 and researches published before the year 2000 were found not very relevant in reference to context of this paper. The rapid growth in the popularity of social media has affected a number of human resource practices (Davison et al., 2010) and as per the Jobvite recruiting survey (Levinson, 2010), more than 73\% of companies have integrated social media networks as part of their overall recruitment strategy. Recruitment trends of any industry can be judged with the help of both the recruiters as well as the individuals seeking job in that industry. Therefore keeping this in mind, we have to study the influence of new Hiring Strategies from both the perspective.

\section{From The Perspective of Recruiter:}

Different researchers have made interesting observations about the new age recruitment strategies.

- The modern and upwardly mobile recruiter has made a dramatic shift from traditional newspaper \& professional journals for placing job advertisements and sourcing candidates, towards internet. With a rapid rise in use of job portals and Social Media.(Parry \& Tyson 2008)

- According to Jobvite's Social Recruiting Survey (2012) that up to 92\% of U.S. recruiters now uses social media and other social networks to recruit and scrutinize employee candidates. This has increased from $78 \%$ in last five year. While most companies use more professional site Linked-In, recruitment through Facebook is done by two thirds and more than $50 \%$ use Twitter to search new talent.

- Melanthious et al. (2015) welcomed new recruitment strategies using social media as a positive change. Arguing that social networking sites not only help recruiters in attracting and locating target applicant it also allows them to carry out background checks. Yet, many recruiters fall short of understanding and taking advantage of the benefits and opportunities that new recruitment channels like social media offers to the recruitment process. Some recruiters even today refrain from using social media as a tool for recruitment.

- On the other hand Compton et al. (2009) and Arlington et al. (2004) argue that recruiters are already using the new age recruitment strategies like social media effectively and acknowledge the fact that social media brings an advantage for their organization providing them easy access to both national and international talent pool. 
- However some researchers like Kilpatrick (2013) suggest social media is not very effective in recruitment process. Because they do not have tools and systems which can be used by the recruiters to develop their judgment or improve their assessment. Nor do they have provisions for methods to manage high numbers of relationships with clients and candidates.

- Contrarily Gallagher and O'Leary (2011) highlight that the social networking sites have the ability of to bring together innovative mixed media along with providing platform for bidirectional communication thus enabling the recruiters to reach both passive as well active job seekers. Educating the job seekers (both active and passive)with regards to Company brand, vacant positions and building a mutually beneficial relationship.

- On the other hand Reiners \& Alexander (2013) argue that it is very critical for both recruiters and job seekers in all countries know and understand social rules that influence the content, style and use of their posted profiles, to accomplish real success in recruitment using social media.

- A study by Workforce (2000) declares that for the companies who make a good use of these new recruitment strategies it has been proven to be up to $30 \%$ faster than other traditional hiring methods. Reason as they claim is the elimination of intercedes and a shorter recruiting cycle.

- Davison, Marathi and Bing (2011) however reflect that the Social Media Sites can be valuable 'friends' for HR, but also have strong possibility of becoming hazardous 'foes' if not used properly".

\section{From The Perspective of Fresh Graduate Engineer Job Seeker:}

- The exponential popularity of Social Media with the new generation has been highlighted by HR firm, Kelly Services (2012) which says that almost 1 in every 5 job aspirants in India access social networking sites for job search.

- Plummer et al. (2009) think that recruitment via social media is not only advantageous for the employers, but it can be beneficial for fresh job seekers as well. It makes the recruitment process more transparent and responsive for the job-seeker since job seekers can access influential referees and gain relevant information in order to better prepare for the pre job screening process.

- Another hiring major Ma Foi -Randstad states (2012) that about 87\% of Indian job seekers employ social media to gather information on the organization and its work culture.

- Free participation and engagement with wider communities (Narvey 2009) is one of the biggest advantages of the social media. Inviting, Sharing and referring each other through social media platform makes recruitment as a very proactive process for both the job seekers as well as the employer. (Eel, Werner, Du Plessis, Fazey, Erwee, Pillay, Mackinnon, Millett \& Wordsworth 2012).

\section{RECRUITMENT STRATEGIES: TRADITIONAL VERSES NEW}

Let us list out and examine few traditional and new recruitment strategies

\section{CONVENTIONAL OR TRADITIONAL RECRUITING PRACTICES}


1) Newspapers: are among the oldest methods of communicating about Job Openings to public. In India even today they are quite popular source of information for a huge population.

2) Government Employment Offices: They usually operate in a wide networked database, training programs for candidates, financial support hiring programs for further assistance. Postings vacancies at local employment offices are/ were a popular and effective way of sourcing people.

3) Internal Hiring: One of the time tested and easiest methods to hire right person for the job is internal hiring. The organization is aware of the existing employee's potential, working styles, background, and performance. This also results in long term commitment from the employee.

4) Temporary Employment Agencies: outsourcing and hiring through temporary employment agencies is one of the most commonly used method used by the organization.. The company HR is spared from initial screening and short listing of candidates and finding suitable people meeting the organization's requirements.

5) Campus Hiring: When the recruitment process is conducted within the premises of educational institution to provide job opportunity to students pursuing or at the completion stage of their enrolled course it is referred to as Campus Hiring or Campus Placements. Companies visit the colleges to mark and pick students based on their skills, ability to work, competence and attitude .The major objective is to select talented and qualified candidates before they complete their education.

Campus Placement is still a very popular recruitment strategy with both the recruiters as well as fresh graduate job seekers

\section{NEW RECRUITING STRATEGIES}

1) Job Portals: Web based job portals like Monster College, naukri.com. Timesjobs.com, cocubes and Aspiring minds etc are example of job portals. They are extensively being used by both the Recruiters as well as the Fresh Graduate Engineer job seekers for their respective searches.

2) Social Media: The popularity of Facebook and Twitter is overwhelming and social media is used more than any other medium today. People use it for almost everything extending from news to updating their job requirements. Organizations and recruiters use this medium to engage with their prospective candidates, employees, and sometimes even with business sponsors.

3) Smart Phones: Smart Phones have has brought the world in the hands of the users and especially the young generation. Any page can be accessed through it. Organizers use this and interact with the candidates by providing info about their companies' online, optimizing company's portal and even using short messaging service (SMS) for communication with fresh graduates.

4) Event Recruitment: Sponsoring events and building brand value is a relatively new and usefulness concept. Companies sponsor events that are related to their ethic value, which they wish to represent through such association. It helps them gain popularity among new generation job seekers and their message goes across a wide spectrum of people. Common 
minded people gather at such places and such events are a great way to recruit suitable employees.

5) Employee Referrals: The existing employees are encouraged to identify and recommend new potential candidates from among their personal and social networks to join and work for the companies. The employee is rewarded with referral bonus, some organizations also link it to their appraisal / Incentive plans. Recruiting candidates using employee referral is widely recognized as one of the most cost saving and effective recruitment method by organizations of all sizes. Companies across all industries are trying it to increase the volume of fresh graduate engineer recruits via internal employee referral.

\section{RESEARCH DESIGN}

An exploratory research was carried out to understand the influence of new hiring strategies employed by the Human Resource Department of various firms and also to understand their relevance for job seekers.

Sample Design: The study covers companies across sectors functioning mainly in North India's National Capital Region (including cities of New Delhi, Adenoid, Burgeon, Ghaziabad, Faridabad, Mohali and Chandigarh). Respondents (HR's) have been chosen using 'Random Sampling Technique'

Data used: For the purpose of this study both Secondary as well as Primary Data has been used

i. Secondary Data- The major source of Secondary data have been online books, articles in journals and company websites.

ii. Primary Data- Primary data have been collected through the "Survey Method" with the help of structured questionnaires.

Two kinds of questionnaires were developed: One for the recruiter and second for the Fresh Graduate job seeker. These two Questionnaires were administered personally to 25 Recruiters and 25 Fresh Graduate Engineer job seekers as respondents.

Scope of the study: HR Managers from 5 companies across different locations in India were selected randomly, and were requested for cooperation to fill the survey questions, as respondents for this study.

They were:

\begin{tabular}{|c|c|c|}
\hline Company Name & Recruiters & $\begin{array}{l}\text { Fresh Graduate } \\
\text { Engineer job seekers }\end{array}$ \\
\hline TCS ( IT Sector) & 5 & 4 \\
\hline ZTE (Electronics and Communication Sector) & 4 & 5 \\
\hline Viom Networks (Electronics Infrastructure Sector) & 5 & 7 \\
\hline SunBeam Auto Pvt Ltd ( Automobiles) & 5 & 4 \\
\hline V Guard Industries Ltd ( Electrical Appliances ) & 6 & 5 \\
\hline
\end{tabular}


Analysis technique: The responses from both the questionnaires were analyzed with the help of graphical representations, bar diagrams and pie charts. Analysis was done and conclusion drawn thereby. Demographics like gender and age and location were not given much emphasis in this study.

\section{RESULTS AND DISCUSSIONS}

1) It was found that the new recruitment Strategies are fast gaining popularity with both the Recruiters as well as the Fresh Graduate Engineer job seekers. Searching for prospective candidates and hiring through Social Media, Job Portals ,Employee Referral and Campus Hiring have emerged as the most popularly used techniques for hiring in that particular order.

2) The primary drivers behind the decision to pursue recruitment channel were rapid technological advancements and fast changing global business scenario apart from surviving challenging and stiff competition.

3) Recruiters are readily using the new age recruitment strategies not only to save cost and time but also for finding the right talent.

4) The jobseekers also have a positive image about the company using the New Hiring techniques.

\section{ADVANTAGES AND DISADVANTAGES OF NEW RECRUITMENT STRATEGIES}

\section{THE ADVANTAGES FOR THE RECRUITERS}

New recruitment Strategies has steered in a new world for Recruiters and Job-seekers alike, full of multitude advantages and benefits. Some more apparent and visible, while others, though less obvious yet significant.

- Operational Improvement: The most evident advantage that the adoption of new recruitment strategies is the high degree of enhancement in recruitment process management. These new strategies facilitate a more controlled. Streamlined and standardized approach throughout every phase of the recruitment process, as compared to the traditional, paperbased recruitment. Screening process such as sorting, coding, filing, and routing application materials which were earlier done manually by the recruiters are now automated thus bringing in a tremendous reduction in the average time of the recruitment cycle.

- Employer Branding: The recruiter can actively build employer brand each day. Every time a recruiter discusses about the average day at the job, special company events or company culture on social media thus attracting a pipeline of excited talented youngsters interested in similar work-life, it is corporate branding even before actual job posting. The new recruitment strategy's positive impacts have surpassed the domains of HR and strengthen the company in other ways, as well. In the era of image, the new recruitment strategies can form an important component of an overarching brand management strategy at a throw away cost. The increase in brand awareness is an intangible but vital variable for winning in today's dynamic \& high eased competitive corporate world.

- Significant Cost Reduction: The new recruitment strategies through Social Media not only improve the efficiency of the recruitment process but also contribute significantly to another 
major benefit that is cost-effectiveness. Although there is a significant cost involved in developing and administering a full-scale recruitment system on corporate web site of the company, recent industry surveys indicate that recruitment costs have declined sharply after the adoption of these new recruitment strategies and systems. Social media sites are mostly accessible without cost. Recruitment of applicants can also be supported by filtering and cross-checking other online resources. This point is very useful for even smaller companies having meager recruitment budget.

- Notably Less Time Consuming: The new recruitment strategies give the advantages of shorter recruitment cycle because of the shift from manual screening, storing and retrieving of applications to automation thus leading to a quicker turnaround time.

- Geographical Spread and Access to Global Competence: Today almost every demographic group has an online presence. Thus another advantage of using the new recruitment strategy is that for the recruiter the available effective range for applicant search is much broader, with the access to both national and international applicants resulting in a larger and diversified talent pool. This advantage is useful not only to gain competitive advantage in the global marketplace but is also the key requirement of modern workplace, where team diversity is highly appreciated.

- Reduces the Average Work Load of the Recruiters: Portion of work load shifted to jobseekers, they have to take onus for the details they publish on their profile and it is their responsibility to make their social media platform look impressive to the employer. Some highly advanced tools employed in the new recruitment strategies enhance their efficiency even further. New applications like eligibility mapping, instant 'fit' assessments, skill-based evaluations, and other metrics can be administered directly to candidates over the Internet. They help in isolating suitable applicants automatically, thus reducing the average workload of HR s considerably.

\section{THE DISADVANTAGES FOR RECRUITERS}

The new recruitment strategies not only contain good amount of merits and advantages but also hold some possible significant limitations and drawbacks as well. Despite the fact that many of the present concerns can be conquered through future technology enhancements yet they call for serious deliberations.

- Major chunk is of non-serious candidates: The overwhelming popularity of social media may result in availability of too many potential applicants. The barriers from the traditional methods, that controlled such non serious candidates, have greatly been eliminated. Now almost every body and anybody can apply online, some non-serious and unqualified candidates, leading to a logistical problem for some companies. A remarkable number is of entry-level applicants that plunge into the job market at the time following college graduation. However most companies report that the number of inappropriate applications is manageable, through automated screening applications and a small price to pay for the overall efficiency and cost-effectiveness realized from adoption of these new recruitment strategies.

- Negative publicity: The Organizations who use social media as part of recruitment strategies are sometimes perceived to be less fair than the ones using traditional methods. The candidate information on the social networking sites may be taken in a negative context by the recruiters and may sometimes lead to hasty rejection decisions. Job seekers 
also view this as part of privacy violations and consider it unfair leading to a negative perception about the HR practices and the company as a whole.

- Authenticity and reliability of information: The information put on the social media sites may not be very systematic and reliable. There are little evidence of verifying the accuracy and authenticity of this information. The data available on social sites may vary considerably making systematic comparison between prospective job seekers difficult.

- Less Humans: since a major portion of the new strategies is through internet some critics and job seekers feel it has to a great extent erased human aspect from the recruitment process, and has become too impersonal. This point is more prominently valid in the current era where intangible factors such as a candidate's organizational fit and the ability to gel with the existing team dynamic are highly critical. To avoid the recruiters must augment these new strategies with traditional one to one personal interaction with the candidates.

- Most qualified applicants may be passive job seekers already engaged and not very interested in the job. To be able to identify and motivate such candidates require a special strategy from the recruiters.

- Lack of confidentiality and security of information on social media sites and online recruitment may discourage the job seekers and hold them from posting job applications.

\section{THE ADVANTAGES FOR THE FRESH GRADUATE ENGINEER JOB SEEKER}

- Multiple services on single window: The new recruitment platforms provide a one stop shop for the job seekers. The candidate not only can access important company information, brand, work culture, job postings as well as apply at the same search attempt thus saving on time.

- Easy access to a lager geographic area for job search: Internet has opened doors of information about global organization as well as job opportunities for young graduates to browse through on simply a click of a button.

- Directly related to specific key skills: More specific job searches related to key skills is possible through the search tools provided by the sites. The job seekers can do this even anonymously.

- Low Cost Platform for job Search: Registration to almost all the social sites is free of cost. The candidates can register, join and even apply through social media sites of the company for free.

- The candidate can job search and apply any time as online application process is open round the clock i.e. $24 / 7$.

- The new recruitment techniques make it possible for contact and increase the traffic of information exchange between the job seekers and the recruiters in person. This creates new collaborations and both can sieve out irrelevant information.

- The social networking sites can be used as job market feelers. The job seekers as well as recruiters can develop, maintain and mobilize their social networking profiles and their social networks more effectively in accordance to the job market demands.

- Quick turnaround time: new recruitment strategies are more transparent and also have significantly reduced the process time and the candidate may have the final outcome in a much lesser time than ever before. 


\section{THE DISADVANTAGES FRESH GRADUATE ENGINEER JOB SEEKER}

- Privacy Problem: The first disadvantage is that of Privacy. Private information posted on Social media sites can leak and easily become accessible to not only family and friends but also to the general public including the recruiters. The entry level young job seekers being fresh out of college may not always realize that the information or even an ordinary comment posted by them can be interpreted in negative sense by the prospective recruiters. They do not sometimes understand the seriousness of posting personal information which might be incorrect. A study indicated that employers reject candidates based on the information on social media. . The top reasons for rejecting applicants included the presence of provocative or inappropriate pictures or information, content like false information about qualifications, bad personal habits, and poor communications skills, derogatory comments about previous employer, discriminatory comments and revealing confidential information from a previous employer. The information posted on the social media raises question on privacy rights of the job seekers once it becomes public. With the job seekers arguing that many times the information may have been posted by others and not by the applicant themselves. This point is still debatable from both recruiters as well as job seekers perspective.

- Less Human: Little or no Personal touch by the recruiters giving rise to perception on lack of fairness in the selection process.

- Doubt on Genuineness The new techniques yet do not have established rules and policies regarding recruitment process thus leading to a lot of confusion on their reliability and authenticity

- Short Vacancy Life cycle: This may result in candidate not receiving timely notification.

- Discrimination against those who do not have personal social media profiles or lack access to high end technological tools.

\section{GRAPHS AND TABLES}

Responses: Recruiters Perspective:

\section{Which of the following according to you is the most effective way of Recruitment}
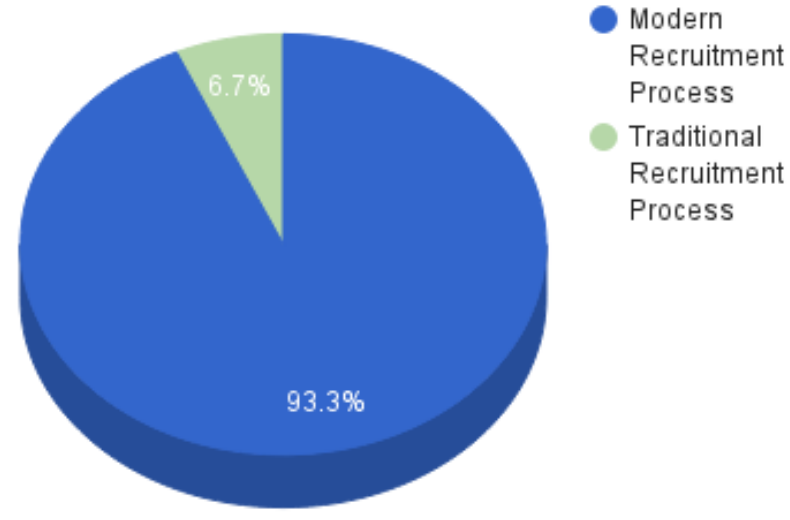
Do you think online recruitment channels are important

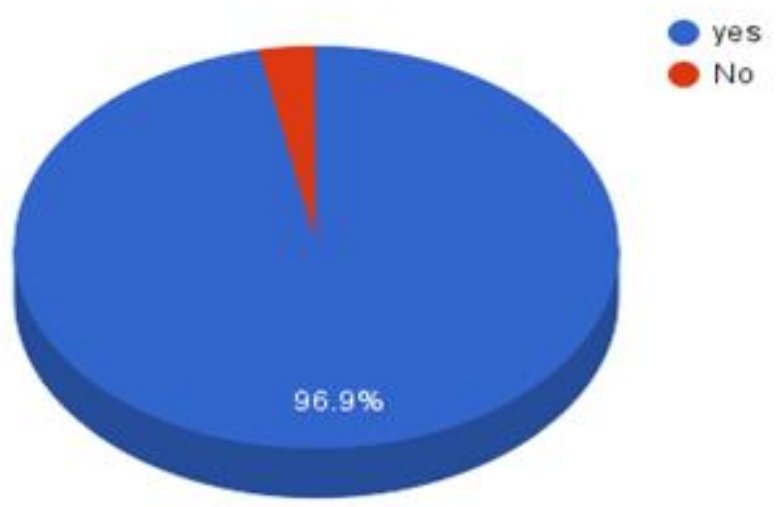

Does change in the global economic scenario altered your choice of recruitment channel

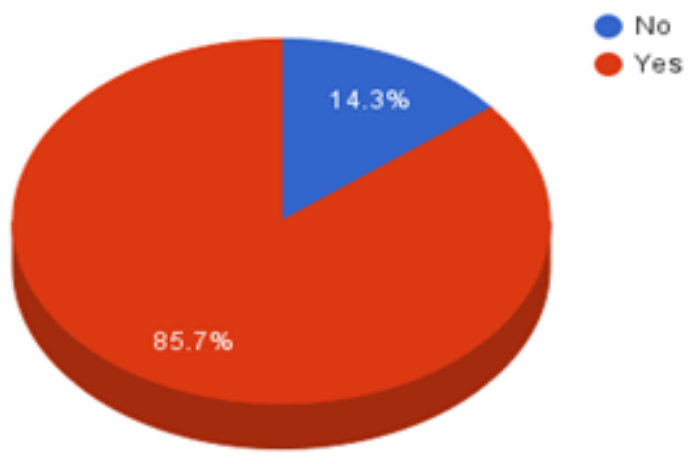

Count of How is the performance of Online Recruitment ( overall return on investment) [very good]
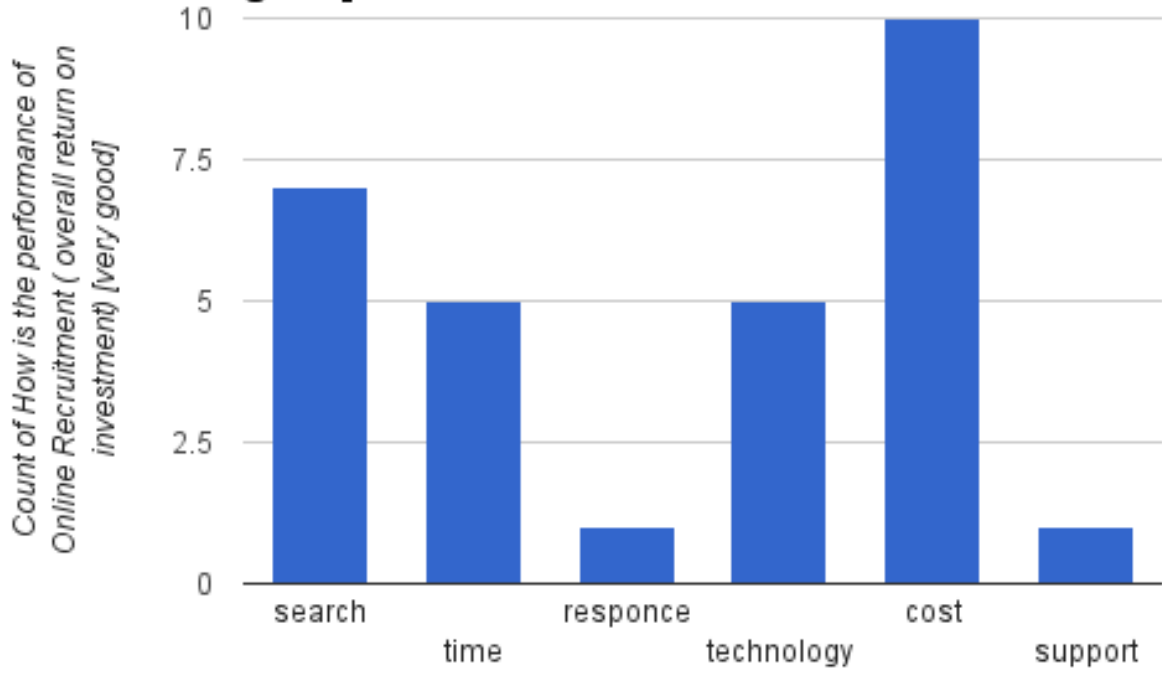

How is the performance of Online Recruitment ( overall return on investment) [very good] 


\section{Are you aware of use of mobile technology as recruitment tool}

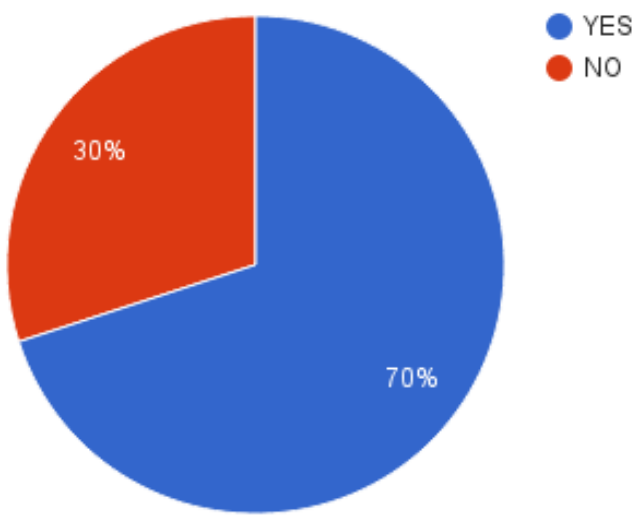

Responses: Fresh Graduate Engineer Job seeker's Perspective:

\section{Which method have you used for Job Search}

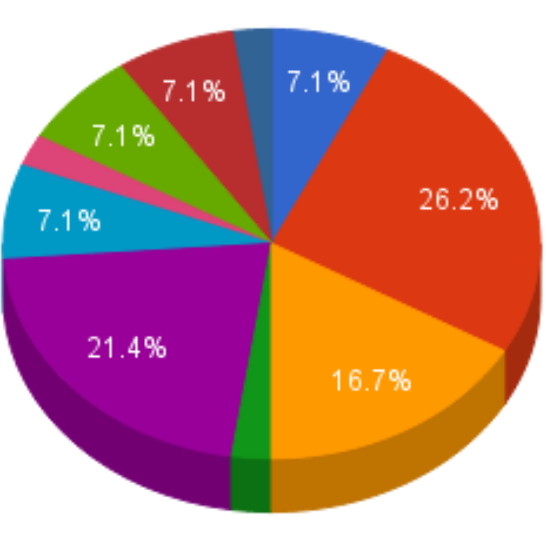

ii.Private Agencies

d)Educational

institutions ( College..

i)Social Networking sites (Facebook, Li..

e)Employee referral

h)Job-Portals ( Naukri. com, Monster .com e...

g)Company website

c)Employment

Agencies

j)Word of mouth

f)Job-fairs

a)Ads in specialist...

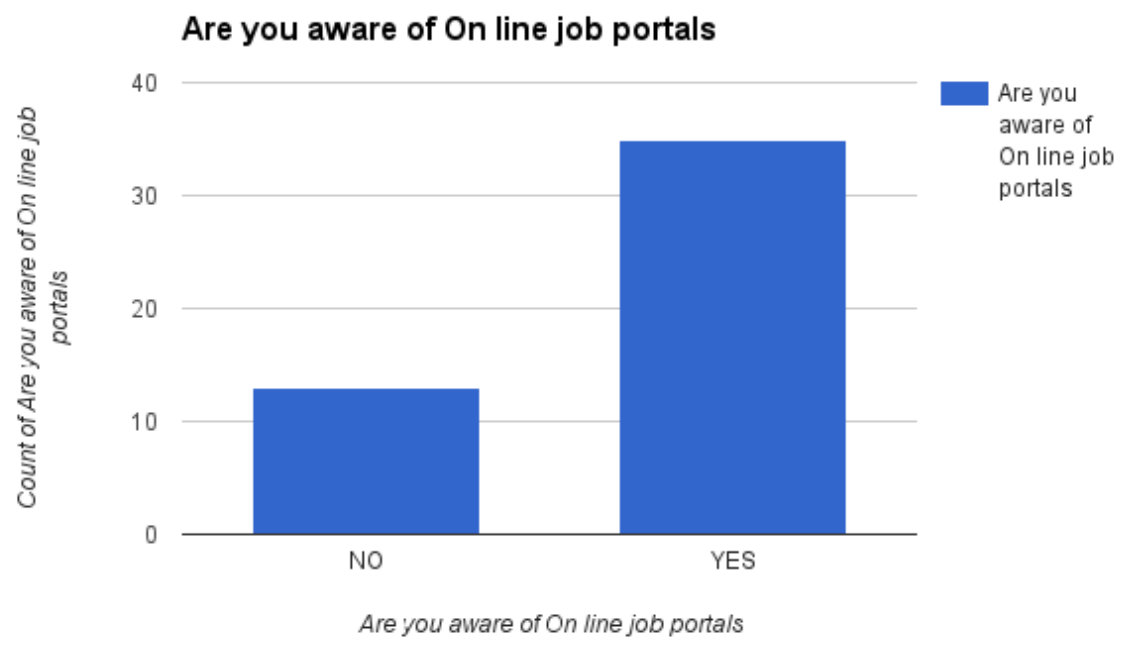



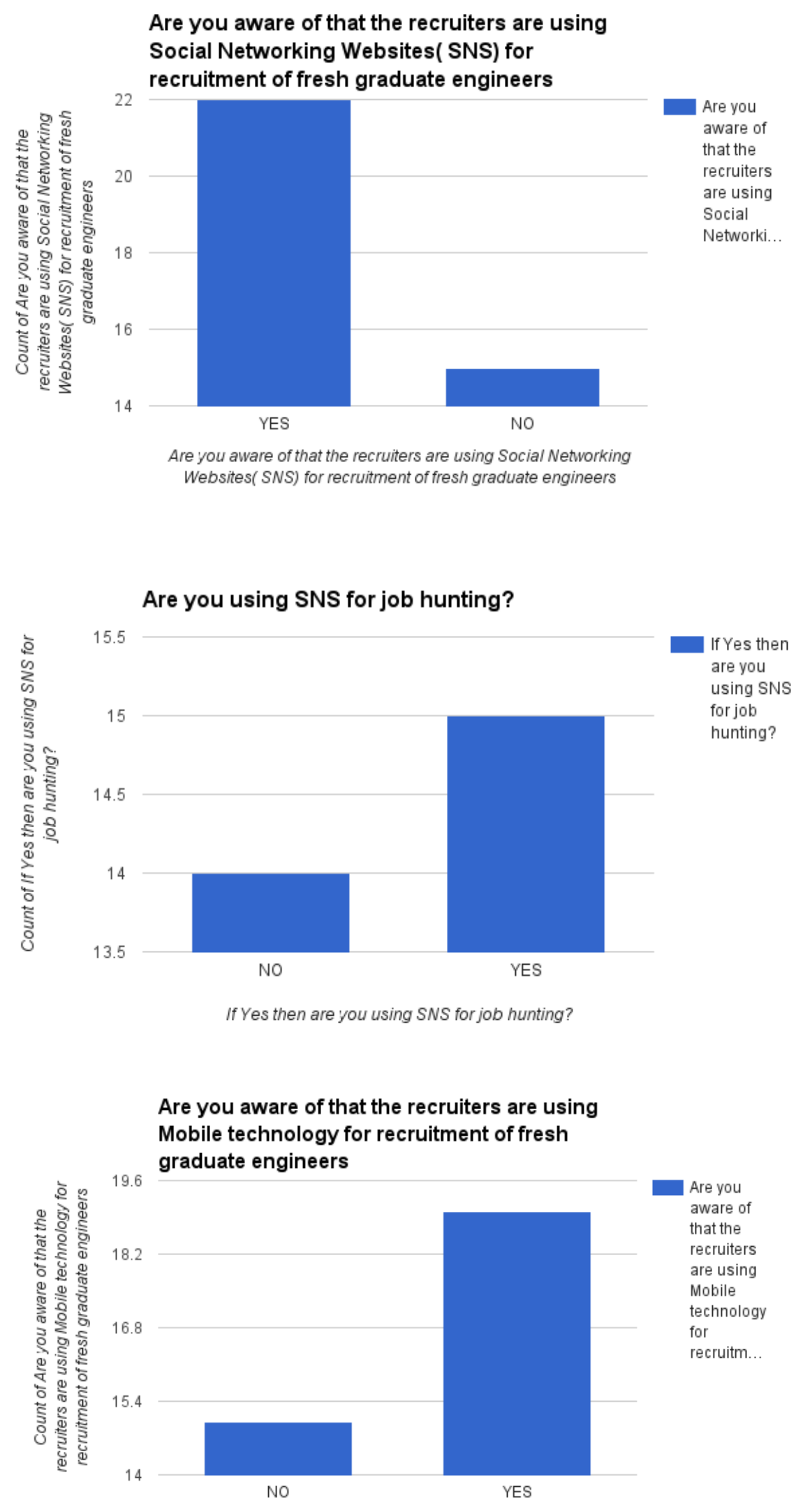

Are you aware of that the recruiters are using Mobile technology for recruitment of fresh graduate engineers 


\section{RECOMEDATIONS}

1) The New age recruitment strategies are not flawless and certain specific job profiles cannot be filled by using these alone. For a meaningful recruitment task they may have to be augmented with other older recruitment methods.

2) Both the recruiters as well as the fresh graduate engineer job seekers can take advantage of the fact that internet and has no space confines long descriptions can be used for job posting work culture as well as candidate profiles.

3) Recruitment through these new strategies is very effective in Branding and building a positive image amongst the new Recruits. Therefore the information being posted has to be carefully scrutinized before publishing by both the parties.

4) It was found that people are using almost $30 \%$ of their online time on social media, and the Recruiter can use this fact for harnessing people having niche or specific skills coupled with extensive persuasion at a later stage since most of the times the job seekers too respond very positively to opportunities offered to them through social media.

5) Ethics, fairness and legal issues must also be considered in detail.

\section{CONCLUSION}

The global dynamic business scenario, advancement of technology and stiff competition particularly have compelled Organizations to replace existing recruitment practices and adopt new Hiring Strategies and practices for continuous growth. New recruitment strategies like online recruitment using Social media are evolving as one of the most effective recruitment tools even job fairs and Campus Recruitments are being augmented with social media. Today almost all Organizations have their own formal pages and websites, where job seekers can learn about the organization business, culture, ethics etc. Studies have indicated that India is the $4^{\text {th }}$ top country in the world in Internet usage. Hence Recruiters have a large pool from this source from which they can search for prospective employees. Eventually these new hiring techniques will take over completely and become the most effective and integral part of the overall Organizations strategic decisions.

\section{REFERENCES}

[1] Jobvite's Social Recruiting Survey 2012 -http://recruiting.jobvite.com/company/pressreleases/2012/jobvite-social-recruiting-survey-2012/.

[2] Alfus, P. (2000) 'Today's Recruitment Practices Require Traditional and Internet Techniques', Hotel and Motel Management, December

[3] Baillie, J. (1996) 'Attracting Employees Who Surf the Internet', People Management, 2:17, 46-47.

[4] Bartram, D. (2005) 'Testing on the Internet: Issues, Challenges and Opprtunities in the Field of Occupational Assessment', in Bartram, D. and Hambleton, R. (eds),

[5] Bartram, D. (2000) 'Internet Recruitment and Selection: Kissing Frogs to Find Princes ',International Journal of Selection and Assessment, 8:4, 261-274.

[6] Bingham, B., Ilg, S. and Davidson, N. (2002), 'Great Candidates Fast: On-Line Job Application and Electronic Processing: Washington State's New Internet Application System', Public Personnel Management, 31:1, 53-64. 
[7] Broek, L.v.d., Derycke, H. and Wijchers, L. (1999) Werven en selecteren voor professionals in Nederland en Belgie, Kluwer, Deventer

[8] Brooke, B. (1998) 'Explosion of Internet Recruiting', Hispanic, 11:12, 68.

[9] Burke, K. (1998) 'Automatic Choices', Personnel Today, 27-28.

[10] CIPD (2005) 'Online Recruitment', [online] (cited 7 December 2005) Available from http://www.cipd.co.uk/subjects/recruitmen/onlnrcruit/onlrec.htm?IsSrchRes $=1$

[11] Cober, R.T., Brown, D.J., Blumenthal, A.J., Doverspike, D. and Levy, P. (2000) 'The Quest for the Qualified Job Surfer: It's Time the Public Sector Catches the Wave',

[12] Dash, J. (1999) 'Job Board "Black Hole”', Computerworld, 33, 62.

[13] Feldman, D.C. and Klaas, B.S. (2002) 'Internet Job Hunting: A Field Study of Applicant Experiences with On-Line Recruiting', Human Resource Management, 41:2, 175-192.

[14] Fister, S. (1999) 'Online Recruiting: Good, Fast and Cheap?', Training, 36, 26.

[15] Freeman, R.B. (2002) 'The Labour Market in the New Information Economy', Oxford Review of Economic Policy, 18:3, 288-305.

[16] Frost, M. (1997) 'The Internet's Hire Purpose', HR Magazine, 42:5, 30-32.

[17] Galanaki, E. (2002) 'The Decision to Recruit Online: A Descriptive Study', Career Development International, 7:4, 243-251.

[18] Greenberg, R. (1998) 'Cast a Wider Net: Online Recruitment', CIO Magazine, 11, 80-88.

[19] Hansen, K.A. (1998) 'Cybercruiting Changes HR, HR Focus, 75:9, 13-16

[20] Haley, J. (2000) 'Corporate Recruiting Strategies: More than Ad Placement' [online] (cited 26 January 2000) Available from http://www.halcyon.com/donace/CRM.HTM

[21] IRS Employment Review (2005) 'Online Recruitment in the UK: 10 Years Older and Wiser', IRS Employment Review, 822, [online] (cited 19 June 2006) Available from http://www.irsemploymentreview.com/DisplayArticle.asp?ArticleID=52687

[22] JWT Research (1998) 'Recruiting on the Net and an Employer's Legal Obligations', [online] (cited 26 January 2000) Available from http://www.hrlive.com/reports/netart2.html

[23] Kaydo, C. and Cohen, A. (1999) 'The Hits and Misses of Online Hiring', Sales and Marketing Management, 151, 13.

[24] Kinder, T. (2000) 'The Use of the Internet in Recruitment: Case Studies from West Lothian, Scotland', Technovation, 20:9, 461-475.

[25] Kuhn, P.J. (2003) 'The Internet and Matching in Labor Markets', in Jones, D.C. (ed) New Economy Handbook, Academic Press, Amsterdam, [online] (cited 25 May 2006) Available from http://www.econ.ucsb.edu/ pjkuhn/Research\%20Papers/Handbook.pdf

[26] Laabs, J.J. (1998) 'Recruiting in the Global Village', Workforce, 77:4, 30.

[27] Lawrence, S. (1999) 'Employment Sites', Iconocast, 10 June, cited in Bartram, D. (2000) 'Internet Recruitment and Selection: Kissing Frogs to Find Princes',

[28] International Journal of Selection and Assessment, 8:4, 261-274, [online] (cited 10 June 2001) Available from http://www.nielsen-netratings.com/hof_off.htm

[29] Lievens, F., Dam, K.v. and Anderson, N. (2002) 'Recent Trends and Challenges in Personnel Selection', Personnel Review, 31:5, 580-601.

[30] McDougall, B. (2002) 'Cyber-Recruitment: The Rise of the E-Labour Market and Its Implications for the Federal Public Service', [online] (cited 25 May 2006) Available from http://www.rma-agrh.gc.ca/research/labour-market/e-recruitment_e.pdf

[31] Mitchell, B. (1998) 'Shortcomings of the Internet', HR Focus, 75, S4. 
[32] Mohamed, A.A., Orife, J.N., and Wibowo, K. (2002) 'The Legality of Key Word Search as a Personnel Selection Tool', Employee Relations, 24:5, 516-522.

[33] Pin, R.J., Laorden, M. and Sáenz-Diez, I. (2001) 'Internet Recruiting Power: Opportunities and Effectiveness', IESE Research Papers D/439, [online] (cited 25 May 2006) Available from http://www.iese.edu/research/pdfs/DI-0439-E.pdf

[34] Piturro, M. (2000) 'The Power of E-Cruiting', Management Review, 89:1, 33-37.

[35] Schreyer, R. and J. McCarter, J. (1998) The Employer's Guide to Recruiting on the Internet, Impact Publications, Manassas Park, VA

[36] Searle, R.H. (2003) 'Organizational Justice in E-recruiting: Issues and Controversies', Surveillance and Society, 1:2, 227-231 [online] (cited 31 May 2006) Available from http://www.surveillance-and-society.org/articles 1(2)/recruiting.pdf

[37] Smith, N. (1999) 'Click and Seek: Headhunting 2000', Management, 46:9, 40-44.

[38] Sullivan (1998) cited by Hays, S. (1999) 'Hiring on the Web', Workforce, 78:8, 76-84.

[39] Veger, M. (2006) 'How Does Internet Recruitment Have Effect on Recruitment Performance?' Fourth Twente Student Conference on IT, 30 January, Enschede, [online] (cited 31 May 2006) Available from http://referaat.cs.utwente.nl/documents/2006_04_DTechnology_organization_and_Innovation/2006_04_D_Veger,M.

How_does_Internet_recruitment_have_effect_on_recruitment_performance.pdf

[40] Young, J. and Weinroth, J. (2003) 'Factors Effecting the Attraction of Qualified Employees to Online Job Postings', [online] (cited 25 May 2006) Available form http:/mismain.bsa.kent.edu/Users/weinroth/public /Nov\%2013\%Jill's\%20paper.doc 